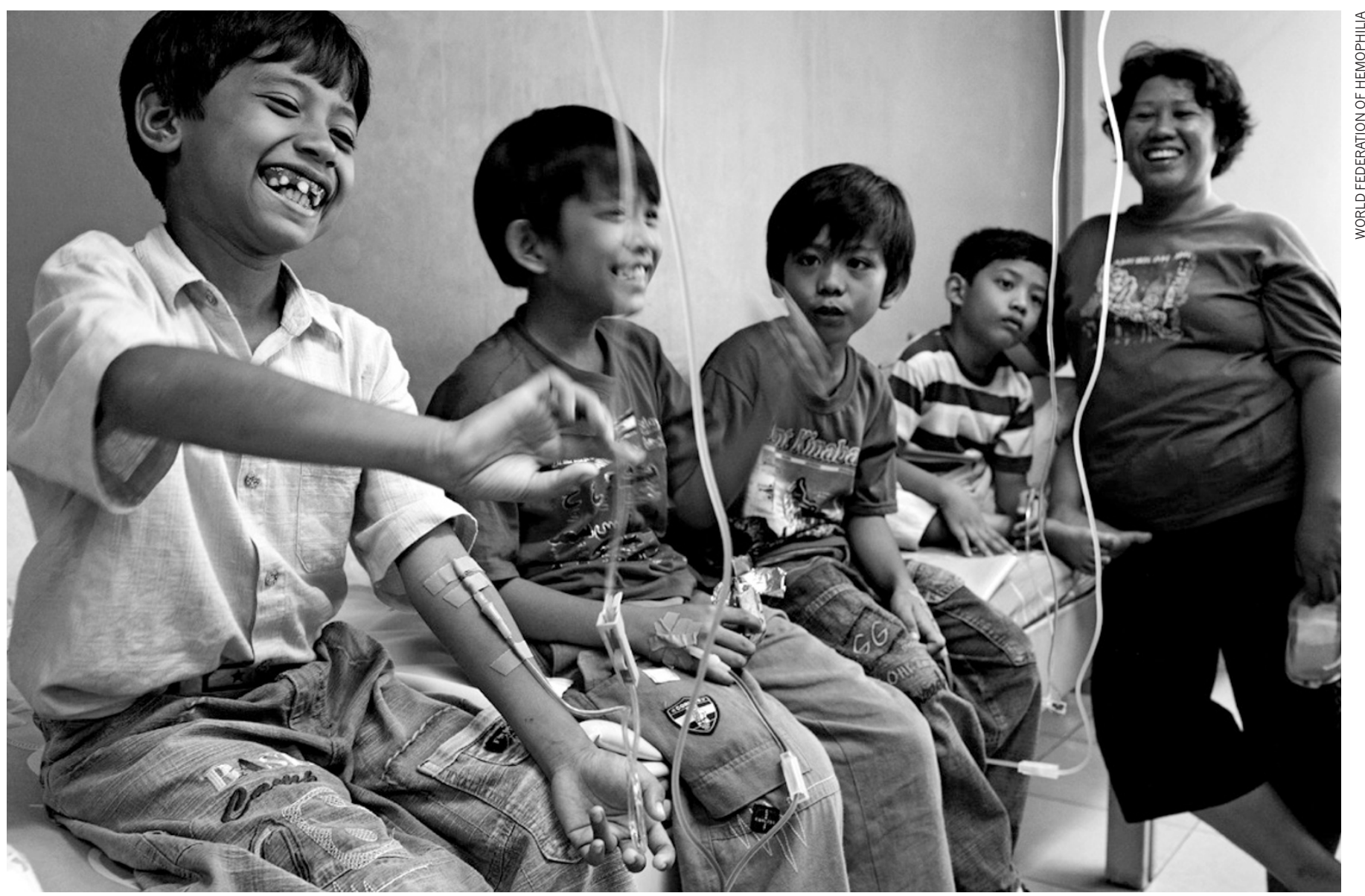

Boys with haemophilia receive a blood-clotting factor by intravenous injection (also referred to as an infusion).

\title{
Stretching time
}

\section{Extending the life of clotting factors may improve quality of life for people with haemophilia.}

\section{BY NEIL SAVAGE}

$\mathrm{F}$ or the parents of a child born with 1 haemophilia, the diagnosis comes with both good and bad news. The good news is that the child, at least if he (or rarely, she) is born in the developed world, can expect a near-normal lifespan, up from a mere 20 years in 1970. The bad is that the parents must teach themselves to find their child's veins, insert a needle and infuse him with a clotting factor to replace what he lacks. Parents must infuse a toddler as often as every other day, and children with haemophilia will have to continue that treatment for the rest of their lives.

But treatment is getting easier. Down the road, gene therapy and other approaches look likely to bring longer-term treatments for patients with the rare bleeding disorder. For now, improvement in treatment lies in the emergence of new, longer-lasting replacements for the blood-clotting factors missing from the blood of people with the condition. These therapies could stretch the time between infusions to days or even weeks. The first two such treatments were approved by the US Food and Drug Administration (FDA) earlier this year, and more are in the pipeline, with some expected to be approved in 2015. As these therapies emerge, dealing with haemophilia will become less troublesome (see 'Drugs to help the blood'). This could increase compliance with treatment, reduce complications - and perhaps even allow some people to live almost as if they were free of the disease.

Replacing the clotting ability lacking in haemophilia has been the treatment since the 1840 s, when attempts were made to treat people with the disease by transfusion with whole blood from people with normal clotting. By the end of the 1960s, freeze-dried concentrates of clotting factors were available for home use, to prevent spontaneous bleeding. In the 1990s, treatment leapt forward again, with donated plasma being replaced by clotting factors manufactured through recombinant DNAtechnology, eliminating the transmission of viral diseases that had devastated the haemophiliac community in the 1970s and 1980s.

But prophylactic treatment still has its problems. The clotting factors do not last very long in the body. Depending on the person, the amount of factor VIII - the protein missing in haemophilia A - in the bloodstream drops by half in a mere 8-12 hours. Factor IX - which people with haemophilia B lack - lasts longer, 18-24 hours. Those short half-lives mean that most people with haemophilia must transfuse themselves every two or three days. And inserting a needle directly into a vein can be difficult. "Adherence to therapy is not great, because you have to inject yourself, and it's a hassle," says David Lillicrap, a professor of pathology and molecular medicine at Queen's University in Kingston, Ontario, Canada.

One 2001 study suggested that up to $40 \%$ of 
people with severe haemophilia do not follow the prophylactic schedule ${ }^{1}$. Those people are more likely to develop spontaneous bleeding that causes joints to fill with blood and results in progressive damage similar to arthritis. They can also develop intracranial bleeding, which can cause brain damage and even death.

Drug companies have responded with clotting factors that last longer, making the time between infusions greater. Biogen Idec, based in Cambridge, Massachusetts, has two such factors approved by the FDA this year. Eloctate, for haemophilia A, was approved in June and is recommended for an initial infusion once every four days, with a physician adjusting that up to five days or down to three as appropriate. Alprolix, the company's treatment for haemophilia B approved in March, promises infusions once a week, and perhaps every ten days or two weeks in some patients. Other versions of the clotting factors from other drug developers are showing similar u extensions of lifetimes.

"It's a big improvement," says Timothy Nichols, a cardiologist and pathologist who studies haemophilia at the University of North Carolina at Chapel Hill. "It's not no treatment, but it is a lot easier than sticking a needle in your kid three times a week."

Steven Pipe, a paediatric haematologist at the University of Michigan's C. S. Mott Children's Hospital in Ann Arbor, agrees that the progress is significant. In particular, work that is stretching the lifetime of factor IX by three to five times is "really transformative", he says. And because half-lives can vary between patients, "at high doses, you could probably in some individual cases get a month's worth of factor IX," Pipe says.

\section{BORROWED TIME}

The trick to extending the half-lives of clotting factors is to interfere with the body's natural mechanisms for flushing them away. There are three very similar approaches, each of which extends half-life by about the same amount for the respective clotting factors. The only real difference is between factor IX, for which the techniques are offering extensions long enough to make a substantial difference in treatment, and factor VIII, for which the improvement has been more modest. Unfortunately, haemophilia $\mathrm{A}$, which is caused by factor VIII deficiency, is about four times as common as haemophilia B.

Two of the techniques piggyback on the half-lives of other longer-lived proteins that occur naturally in the body. One such is immunoglobulin, a large Y-shaped protein with a half-life of about three weeks. The stem of the $\mathrm{Y}$ is known as the $\mathrm{Fc}$ region. When a clotting protein is fused to an Fc region, the body treats the clotting factor more like an immunoglobulin, and allows it to stick around for longer, although not for as long as a complete immunoglobulin molecule.

\section{DRUGS TO HELP THE BLOOD}

A number of treatments to aid blood clotting are in clinical trials or have been approved this year.

\begin{tabular}{|c|c|c|c|c|c|}
\hline & Product & Approach & Company & $\begin{array}{l}\text { Half-life } \\
\text { (hours) }\end{array}$ & Status \\
\hline \multirow{2}{*}{$\begin{array}{l}\text { Factor VIII } \\
\text { infusions (for } \\
\text { haemophilia A) }\end{array}$} & Eloctate & $\begin{array}{l}\text { Fc fusion } \\
\text { protein }\end{array}$ & Biogen Idec & 20 & $\begin{array}{l}\text { FDA approved in June } \\
2014\end{array}$ \\
\hline & $\begin{array}{l}\text { BAX } \\
855\end{array}$ & PEGylation & Baxter International & 19 & $\begin{array}{l}\text { Submission for approval } \\
\text { planned for late } 2014\end{array}$ \\
\hline \multirow{2}{*}{$\begin{array}{l}\text { Conventional } \\
\text { infusion half- } \\
\text { life: } 8-12 \text { hours }\end{array}$} & $\begin{array}{l}\text { BAY94- } \\
9027\end{array}$ & PEGylation & Bayer & 19 & $\begin{array}{l}\text { Submission for approval } \\
\text { planned for mid- } 2015\end{array}$ \\
\hline & N8-GP & PEGylation & Novo Nordisk & 19 & $\begin{array}{l}\text { Submission for approval } \\
\text { planned for } 2018\end{array}$ \\
\hline \multirow{2}{*}{$\begin{array}{l}\text { Factor IX } \\
\text { infusions (for } \\
\text { haemophilia B) }\end{array}$} & rIX-FP & $\begin{array}{l}\text { Albumin } \\
\text { fusion }\end{array}$ & CSL Behring & 92 & $\begin{array}{l}\text { In clinical } \\
\text { trials }\end{array}$ \\
\hline & N9-GP & PEGylation & Novo Nordisk & 110 & $\begin{array}{l}\text { Submission for approval } \\
\text { planned for } 2015\end{array}$ \\
\hline $\begin{array}{l}\text { Conventional } \\
\text { infusion half- } \\
\text { life: 18-24 } \\
\text { hours }\end{array}$ & Alprolix & $\begin{array}{l}\text { Fc fusion } \\
\text { protein }\end{array}$ & Biogen Idec & 87 & $\begin{array}{l}\text { FDA approved } \\
\text { in March } 2014\end{array}$ \\
\hline
\end{tabular}

FDA, US Food and Drug Administration.

For factor VIII, Fc fusion extends the half-life from a maximum of about 12 hours to about 18 hours. Factor IX, which has a longer half-life to begin with, shows a more dramatic increase, from one day to five days.

Both the approved Biogen drugs are based on Fc fusion. Similar fusion drugs have been on the market to treat other diseases for many years, for example the rheumatoid arthritis drug Etanercept, which was approved by the FDA in 1998. Jerry Powell, the retired director of the Hemophilia Treatment Center at the University of California, Davis, says that the success of those drugs suggests that this is a safe approach to altering the clotting factors.

A similar approach, which is being pursued by CSL Behring, based in King of Prussia, Pennsylvania, is to fuse the clotting factors with albumin. Albumin is a major protein of blood plasma and, like immunoglobulin, has a half-life of about 20 days. Phase I safety studies of factor IX fused to albumin showed a fivefold increase in half-life, up to about four days. Unfortunately, attempts to do the same with factor VIII have been unsuccessful. Powell says that the albumin seems somehow to interfere with the normal activity of that clotting factor.

"These are really big molecules," he says. The activity of factor VIII in action, he adds, is so complex that it resembles a dancing elephant - too easily thrown off its rhythm when something else is attached. "If you put the wrong kind of contraption on the elephant, it doesn't dance as well."

The third strategy takes a slightly different approach. Instead of marrying the clotting proteins to a natural substance in the body, they are attached to synthetic polyethylene glycol (PEG) molecules (see 'PEGylation protection'). The PEG forms a sort of 'watery cloud' around the protein, protecting it from various mechanisms that would break it down; for instance, PEG prevents the clotting factors from binding to protein-specific receptors that would normally clear them away. PEG is eventually flushed from the body through the kidneys and liver, but before then it gives the clotting factors a new lease of life. Three large drug companies - Bayer in Leverkusen, Germany, Baxter International in Deerfield, Illinois, and the Danish company Novo Nordisk in Bagsvaerd - have all developed PEGylated factor VIII with a half-life of roughly 19 hours. Baxter expects to submit its product for regulatory approval by the end of this year, Bayer next year, and Novo Nordisk by 2018 .

Novo Nordisk is also testing a PEGylated factor IX that has shown a half-life of 110 hours in clinical studies. The company says that it hopes to submit that drug for approval next year.

Up to now, tests have not shown much difference, in safety or effectiveness, between the three approaches. There are concerns that PEG might accumulate in the liver or kidneys over years of use, but studies of PEG have found it to have very low toxicity, and Powell thinks that those fears are exaggerated ${ }^{2}$. 'PEG's been around a long time, there's a lot of toxicology and all the toxicology indicates no concern," Powell says. And if, as he expects, gene therapy replaces these treatments in the next decade, patients will in any case not have lifetime exposure to PEG.

One barrier to haemophilia therapy is the tendency of factor VIII to prompt the body into producing anti-factor VIII antibodies, 
known as inhibitors. For a person with haemophilia A, factor VIII is a foreign substance, and the immune system can see it as a threat. About $30 \%$ of people with haemophilia A develop inhibitors, and once they do, treating their bleeding becomes much more difficult. Only about $4 \%$ of people with haemophilia B develop inhibitors to factor IX.

There is a lot of worry, Pipe says, that altering factor VIII to extend its half-life could make the inhibitor problem worse. "Everyone treads lightly in the factor VIII field, because there is such a fear of immunogenicity with any change of the molecule," he says. "There's no question with the current strategies that all of them have sort of hit a ceiling. If we're really going to overcome that ceiling, you are going to have to accept more dramatic changes to the molecule."

PEG may prove helpful in that regard. Studies dating back to the 1970s have shown that PEGylation can reduce the chances of a foreign protein stimulating an immune reaction, although the effect has not yet been proved in people with haemophilia. "That'd be a huge breakthrough if that were true," Powell says.

\section{CONSTANT CASCADE}

One researcher might have worked out a way to avoid the inhibitor issue almost entirely, by developing a different molecule to take the place of factor VIII in the clotting cascade.

Normally, once activated by previous steps in the cascade, factor VIII grabs hold of both factor IX and factor X, bringing them together to perform the next steps in the cascade. Midori Shima, director of the Hemophilia Center at Nara Medical University in Japan, has created a 'bispecific' antibody to do the same job.

Antibodies are immunoglobulins, and the upper arms of these Y-shaped proteins are designed to bind specifically to another molecule. Shima has created an antibody with one arm that binds to factor IX and the other to factor X, pulling the two together so that the clotting cascade can continue. The bispecific antibody has a half-life of about 30 days, much longer than the 12-hour upper limit of factor VIII, Shima says. Chugai Pharmaceuticals, based in Tokyo, and Hoffman-La Roche, based in Basel, Switzerland, are working on developing his findings into a treatment.

The researchers have not yet released the results of their phase II initial clinical trials, but Shima says that in the patients with haemophilia they looked at, bleeding frequency decreased dramatically. Among six people receiving the lowest dose of the treatment, who had each had 20-60 episodes of bleeding in the 12 weeks before the trial, two had no bleeding episodes at all during the 12 weeks of the trial. And out of 64 patients, only one developed an inhibitor. The team is planning a larger, phase III trial.

One bonus of this treatment is that because

\section{PEGylation protection}

A key advance in haemophilia treatment is to prolong the effectiveness of the injected coagulation-promoting proteins (clotting factors) by shielding them from destruction.

\section{BEFORE}

\section{Unprotected molecule}

Under normal circumstances, proteases and protein-specific receptors break up the clotting factor and rapidly clear it from the bloodstream.

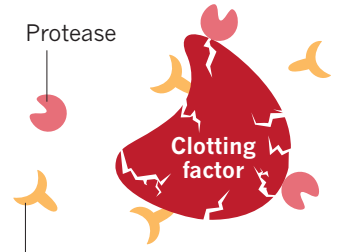

Protein-specific receptor

\section{AFTER}

\section{Microscopic shield}

In PEGylation, molecules of polyethylene glycol (PEG) are attached to the clotting factor. The PEG molecules bring with them water molecules, which shield the clotting factor from attack.

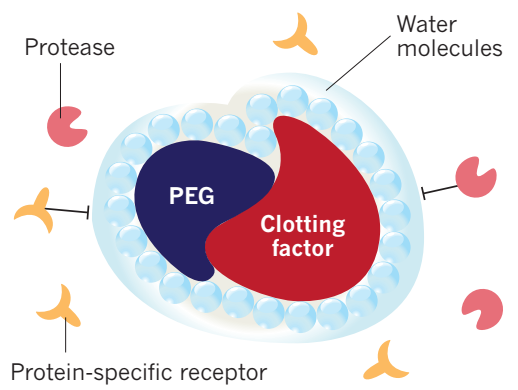

\section{Too big to discard}

The watery cloud makes the factors too big for the kidneys' filtration mechanism, so the molecule circulates in the bloodstream for longer.

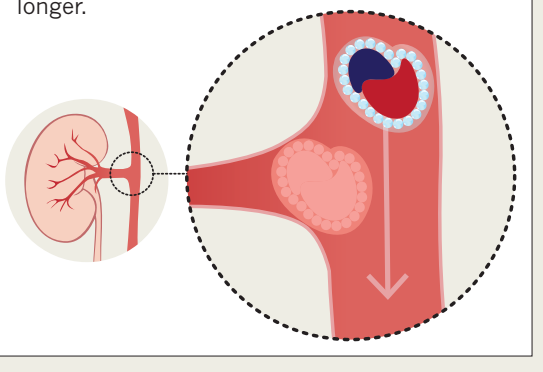

of the nature of the antibody, it does not have to be delivered intravenously, but instead can be injected under the skin, like insulin. "We think we can change the whole concept of haemophilia treatment," Shima says.

Lillicrap agrees. "That bispecific antibody would be hugely disruptive if it works," he says. "We'll know within the next couple of years whether it delivers on the promise which so far it's shown."

Treatments with extended half-lives may provide benefits beyond the convenience of less-frequent infusions and the potential increase in the number of people who stick to their treatment regime. If people under treatment now keep to their current schedule with the extended-life products instead of taking fewer infusions, the increased concentration of clotting factors in their blood could improve their quality of life even further.

When patients have "It is a lot an infusion of clotting easier than sticking a needle in your kid three times a week." factor every 48 hours, the concentration of clotting factor initially reaches $100 \%$ of normal levels and stays there for about 12 hours. For the next 36 hours, it is high enough to be useful, but below normal. For the last 6 to 8 hours, the level is very low, less than $5 \%$, Pipe says. Physicians try to keep the lowest level, the trough, from falling below 1\% of the amount a non-haemophiliac person has circulating in their blood, enough to prevent spontaneous bleeding.

But if the trough level can be higher, it might make life easier for the patients, allowing them to, for instance, take up athletics with less fear of injury. "Ideally, you'd like to have zero bleeding," Pipe says. "What is the threshold for that I don't think anybody knows." Still, there would be substantial benefit from a less-than-perfect level of clotting factor. "If you could maintain a level of $10 \%$ or $15 \%$, you would probably eliminate all joint disease," he says.

Lillicrap hopes that the emergence of several therapies means that it will make economic sense for drug companies to provide treatments to poorer parts of the world that have not been able to afford them. "No longer are people thinking about these therapies being only Western European and North American therapies," he says. If pharmaceutical companies are pouring money into this research, he thinks that it is at least in part because they can see a worldwide profit benefit.

For all the advantages of these extendedlife molecules, the researchers predict that they will be supplanted in perhaps a decade by advances in gene therapy, which will enable people with haemophilia to produce their own clotting factors. But in the meantime, trading current therapies for longer-lasting ones can improve patients' lives. "As a bridging therapy between the really good outcomes we have currently and maybe a cure down the line," says Pipe, "I think the extended-half-life molecules are a perfect transition."

Neil Savage is a freelance writer based in Lowell, Massachusetts.

1. Hacker, M. R., Geraghty, S. \& Manco-Johnson, M. Haemophilia 7, 392-396 (2001)

2. Webster, R. et al. Drug Metab. Dispos. 35, 9-16 (2007). 